\title{
ENSINAR QUÍMICA JOGANDO BINGO
}

\section{TEACHING CHEMISTRY THROUGH THE GAME OF GAME}

\author{
Rodrigo Ruschel Nunes* \\ Kathia Regina Kunzler** \\ Silvia Costa Beber ${ }^{* * *}$
}

\section{RESUMO}

Este trabalho apresenta o relato de uma experiência com o jogo "Bingo Químico" com estudantes da primeira série do Ensino Médio. O jogo foi utilizado para trabalhar conceitos de tabela periódica, objetivando estabelecer a relação entre nome e símbolo dos elementos químicos e despertar o interesse dos estudantes na disciplina de Química. Anteriormente ao desenvolvimento do jogo o professor trabalhou os conceitos do conteúdo, enfatizando a presença dos elementos químicos em materiais e tecnologias presentes no cotidiano. Posteriormente ao jogo, os estudantes responderam um questionário contendo questões sobre o conteúdo e percepção da atividade. Constatamos que essa atividade desempenhou sua função, pois tanto o caráter educativo como o lúdico foram observados como mediadores e propulsores da aprendizagem de conteúdo de Química nesse nível de ensino. Destacamos a necessidade de incorporar a pesquisa nas práticas com jogos como eixo norteador do trabalho docente, pois sabemos que a reflexão na ação possibilita uma intervenção consciente nos processos de ensino e aprendizagem.

Palavras-chave: Tabela Periódica. Lúdico. Jogo.

\begin{abstract}
This paper reports an experience with the game "Chemical Bingo" with students of the first year of Senior High School. The game was used to practice the concepts of the periodic table aiming to establish a relation between the name and the symbols of chemistry elements and raise the interest of students for the learning of Chemistry. Before the game the teacher explained concepts emphasizing the presence of chemical elements in materials and technology used by students in their daily routines. After the game the students answered a questionnaire about the concent and their perception of the game. It was observed that the activity
\end{abstract}

\footnotetext{
"Mestre em Ensino de Ciências pela Universidade Federal de Campo Grande, graduação em Química-Licenciatura pela Universidade Federal de Santa Maria. Atualmente é professor do Departamento de Química da Universidade Estadual do Oeste do Paraná (UNIOESTE-PR). < rodrigonunesunioeste@ gmail.com.br>.

${ }^{* *}$ Mestre em Engenharia Agrícola - linha de pesquisa: Recursos Hídricos e Saneamento Ambiental na Universidade Estadual do Oeste do Paraná (2010). Atualmente é professora efetiva do Instituto Federal do Paraná - IFPR e professora assistente da Universidade Estadual do Oeste do Paraná - UNIOESTE. <kathiark@yahoo.com.br>

**** Mestre em Educação pela Universidade de Passo Fundo (2006). Atualmente é professora assistente da Universidade Estadual do Oeste do Paraná/UNIOESTE, atuando na área de Educação Química do Centro de Engenharias de Ciências Exatas - CECE.<silviacostabeber@hotmail.com>
} 
fullfilled its function as both the educational and playful aspects were considered as mediators of Chemistry learning for students of the level involved in the research. The article points out to the need of incorporating research in teaching practices that use games as one of its guiding elements, as it is known that reflection about practice provides a conscious intervention in teaching-learning processes.

Keywords: Periodic table. Playful activities. Game.

\section{Introdução}

A busca por recursos diferenciados no processo de ensino vem se tornando cada vez mais constante, dada a dificuldade encontrada pelos docentes em despertar o interesse dos estudantes pelos conteúdos apresentados. Atualmente, de acordo com Cunha (2012), o insucesso na aprendizagem - antes creditado ao baixo empenho dos estudantes - vem sendo cada vez mais considerado como uma consequência do trabalho do professor, e este, diante disso, tem buscado situações estimuladoras da aprendizagem.

Utilizar estratégias simples e de baixo custo tem sido o foco dos educadores diante dos recursos disponíveis na maioria das instituições de ensino. No ensino de Química, o que se observa é o uso cada vez maior da experimentação e jogos didáticos a fim de dinamizar o processo de aprendizagem (SOARES et al., 2003).

Para que essa orientação se transforme em uma realidade concreta, a interação do sujeito com o objeto a ser conhecido é essencial. Assim, a multiplicidade na proposta de jogos didáticos concretiza e materializa as interações nela realizadas (ANTUNES, 1998).

Cabe-nos, neste momento, explicitar nossa compreensão sobre o significado do jogar, a partir dos diferentes estudos que subsidiaram nossas reflexões. Destacamos as primeiras contribuições de Huizinga (1996, p.10):

O jogo é uma função da vida, mas não é passível de definição exata em termos lógicos, biológicos ou estáticos. O conceito de jogo deve permanecer distinto de todas as outras formas de pensamento, através das quais exprimimos a estrutura da vida espiritual e social.

O brincar está presente na vida humana desde o nascimento e ocupa uma dimensão mais ampla do que se pode mensurar pelos estudos científicos que primam pela lógica, racionalidade e técnica. Jogar ou brincar são fundamentais na interação do homem com seu meio e com os demais que participam desse meio. Ficam evidentes os processos de aprendizagem promovidos pelo brincar da criança, bem como continuam presentes os benefícios do brincar - caracterizado principalmente pelos jogos - nas interações sociais que o homem continua mantendo por toda a sua vida.

Oliveira (2000, p. 17) faz outro comentário em relação ao brincar:

Aprender a agir, inclusive a brincar, só se dá em contato íntimo e significativo com o outro que, via de regra, no início da vida, é a mãe ou quem a substitua. Não há possibilidade de aprendizagem e consequentemente de humanização fora do convívio social e, mais do que isso, sem vivenciar e sentir realmente um vínculo afetivo, estável e confiável, que no começo é muito mais sentido do que manifesto.

A dimensão socializadora do brincar é salientada por Oliveira (2000), que aponta essa necessidade como a primeira manifestada na criança e que se estende até a vida adulta, ao manter contato e relação social. Essas interações são importantes por possibilitarem uma aprendizagem espontânea, a qual, gradativamente, chega ao conhecimento científico correlato. Com relação ao jogo junto aos processos de interação e aprendizagem na escola, Negrini (1994, p. 19) ressalta:

As contribuições do jogo no desenvolvimento integral indicam que ele contribui poderosamente no desenvolvimento global da criança e que todas as dimensões do jogo estão intrinsecamente vinculadas: a inteligência, a afetividade, a motricidade e a sociabilidade são inseparáveis, sendo que a afetividade constitui a energia necessária para a progressão psíquica.

A dinamicidade dos jogos pode ser entendida quando verificamos que, além de sua natureza instrucional, eles possuem características lúdicas, que incorporam aspectos afetivos e tornam o 
ensino e a aprendizagem atividades significativas. Isso funciona, tendo o professor como organizador do ensino, respeitando as decisões dos alunos e materializando a intencionalidade do ato educativo (KISHIMOTO, 2001).

Segundo o dicionário da Língua Portuguesa, jogo é a atividade física ou mental fundada em sistema de regras que definem a perda ou o ganho. Para isso são estabelecidas regras e também objetivos.

O uso de regras é a característica principal do jogo. Huizinga (1999) reconhece o jogo como uma atividade livre, porém que tem regras a serem respeitadas, dizendo até que o jogador que desrespeita as regras é um "desmancha-prazeres", pois sem as regras o jogo perde o seu sentido:

Numa tentativa de resumir as características formais do jogo, poderíamos considerá-lo uma atividade livre, conscientemente tomada como "não-séria" e exterior à vida habitual, mas ao mesmo tempo capaz de absorver o jogador de maneira intensa e total. É uma atividade desligada de todo e qualquer interesse material, com a qual não se pode obter qualquer lucro, praticada dentro de limites espaciais e temporais próprios, segundo uma certa ordem e certas regras. (HUIZINGA, 1999, p. 16).

Apesar da utilização de regras no jogo, ele é uma atividade, na maioria das vezes, prazerosa. Existem vários tipos de jogos (jogos esportivos, jogos de lazer, jogos tradicionais etc.), entre os quais há vários que trabalham com raciocínio, percepção visual, que são ótimos aliados na aprendizagem escolar. Cabe ao professor saber o momento correto de utilizar o jogo e também o tipo de jogo mais adequado ao conteúdo com o qual vai trabalhar, mais condizente com os seus objetivos.

Friedmann (1996) tece alguns comentários sobre os termos que acabamos de especificar:

É importante ressaltar, neste momento, a definição de alguns termos utilizados: brincadeira refere-se, basicamente, à ação de brincar, ao comportamento espontâneo que resulta de uma atividade não estruturada; jogo é compreendido como uma brincadeira que envolve regras; brinquedo é utilizado para designar o sentido de objeto de brincar. (FRIEDMANN, 1996, p. 12).

Jean Piaget cita, em diversas de suas obras, fatos e experiências lúdicas aplicadas, e deixa transparecer claramente seu entusiasmo por esse novo processo. Para ele, os jogos não são apenas uma forma de desafogo ou entretenimento para gastar energias, mas meios que contribuem para o desenvolvimento intelectual e o enriquecem. Na tentativa que a criança e o adolescente fazem para assimilar uma realidade, e não possuindo ainda estruturas mentais plenamente desenvolvidas, eles aplicam os esquemas de que dispõem, reconstruindo esse universo próximo com o qual convivem. (PIAGET apud ALMEIDA, 1987, p. 20).

Para Piaget (1978), os jogos tornam-se mais significativos à medida que a criança se desenvolve, pois a partir da livre manipulação de materiais variados, ela passa a reconstruir objetos, reinventar as coisas, o que já exige uma adaptação mais completa. Essa adaptação, que deve ser realizada na infância, consiste numa síntese progressiva de assimilação com a acomodação que vai sendo construída até chegar às relações operatórias concretas. É por isso que, pela própria evolução interna, os jogos das crianças se transformam pouco a pouco em construções adaptadas, exigindo sempre mais do trabalho efetivo, a ponto de, nas classes elementares de uma escola ativa, todas as transições espontâneas ocorrerem entre o jogo e o trabalho, e em especial na adolescência.

"Desde Claparède e Dewey, Wallon e Piaget está bastante claro que a atividade lúdica é básica para atividades intelectuais e sociais superiores" (LEIF; BRUNELLE, 1978, p. 114). Nesse sentido, pode-se dizer que as atividades lúdicas são indispensáveis para a prática educativa.

Assim, o uso de jogos no ensino de Química tem sido foco de trabalhos de diversos autores, os quais destacam a eficiência dos jogos em despertar o interesse dos estudantes. Cunha (2012) considera que os jogos podem ser utilizados como auxiliares na construção de conhecimentos em qualquer área do ensino. Segundo Godoi et al. (2009), os jogos didáticos são bons auxiliares para o ensino de conteúdos considerados de difícil compreensão. De acordo com Soares (2008), é possível observar que os jogos didáticos facilitam a aquisição de conceitos, a relação com o concreto, além de transformarem a sala de aula em um ambiente de prazer, onde o estudante encontra-se mais à vontade para manifestar seus conhecimentos.

Segundo Costa et al. (2005), durante a participação no jogo, os alunos aprendem a respeitar 
o outro, compreendendo suas próprias limitações e edificando novos aprendizados e valores. $\mathrm{O}$ aluno percebe sua capacidade de resposta, o quanto sabe, e com isso torna-se confiante na busca de soluções.

Kishimoto (1996) afirma que para que um jogo possa ser denominado educativo (ou didático), deve apresentar duas funções: função lúdica - o jogo proporciona diversão, e função educativa - o jogo ensina qualquer coisa que complete o saber do jogador. Quando uma dessas funções é utilizada em demasia em relação à outra, ocorrem duas situações: se a função lúdica é a que se sobressai à função educativa, tem-se apenas o jogo; porém, se a função educativa se sobressai à função lúdica, tem-se um material didático. Logo, é importante que o educador saiba equilibrar essas duas funções no jogo, para que se tenha de fato um jogo educativo.

O presente trabalho utilizou um jogo didático produzido para auxiliar na construção do conhecimento da disciplina de Química abordado na primeira série do Ensino Médio. A implementação do mesmo foi efetuada com o objetivo de verificar a pertinência desse recurso na construção do conhecimento, levando os alunos a uma melhor compreensão dos nomes e símbolos dos elementos químicos e ajudando os professores na busca de uma prática pedagógica crítica, criativa e inovadora.

Tendo em vista que os alunos do Ensino Médio, de modo geral, demonstram certo receio pela disciplina de Química, por considerarem de grande dificuldade a memorização dos nomes e respectivos símbolos dos elementos químicos da tabela periódica, o jogo de bingo foi utilizado, com o objetivo de estimular os estudantes na compreensão desses nomes e símbolos, assim como despertar o seu interesse para a disciplina de Química e sua linguagem.

\section{O jogo e a formação do professor}

Para a introdução de um trabalho que contemple o lúdico, a organização pedagógica e o respeito às diferenças socioculturais do aluno na educação, a meta fundamental é a formação dos professores.

O verdadeiro e real sentido da educação lúdico-pedagógica estará garantido, se o professor estiver preparado para realizá-la. Nada será feito se ele não tiver um profundo conhecimento sobre os fundamentos essenciais da educação lúdica e do jogo, da organização pedagógica, e não respeitar o ritmo de cada aluno, condições suficientes para socializar o conhecimento e predisposição para levar isso adiante.

Os alunos de hoje estão na situação de só acreditar nos professores que ainda sabem participar, sabem transformar suas aulas em trabalho-jogo (seriedade-prazer), sabem manter um relacionamento de irmãos mais velhos. Sabemos também que quando os alunos gostam do professor, acabam gostando daquilo que ele ensina e se esforçam cada vez mais para aprender e não decepcionar. Quando uma criança sente que é amada, respeitada pelo professor e pela escola, sua permanência na escola se fortalece, e só uma causa muito forte a faz abandonar a escola. (ALMEIDA, 1987, p. 42).

Precisamos ter consciência de que, quando um professor desperta no adolescente a paixão pelos estudos, ele mesmo buscará o conhecimento e fará tudo para corresponder e não decepcionar. Quando um aluno descobre que a maior e melhor educação escolar e não escolar é aquela que existe nele mesmo, ele se encarregará de buscar os conhecimentos e as experiências.

Isso tudo se resume em: saber, despertar, conscientizar e confiar. A escola de hoje, por meio de seus professores, ainda não aprendeu a confiar no aluno. Dá o conhecimento, impõe o saber e o cobra, com medo de que os alunos não o dominem.

Tolhe-se a liberdade de os alunos buscarem novos conhecimentos, novos caminhos, enquadrando-os em horários rígidos e estudos regulamentados. Os professores não suportam a mobilidade do aluno e querem que o aluno suporte a sua imobilidade.

$\mathrm{O}$ que precisamos é recuperar o verdadeiro sentido da palavra escola, mas não sob a ótica da concepção de escolarização, e sim sob a ótica da concepção da educação em seu sentido mais amplo, e como lugar de alegria, prazer intelectual, satisfação.

É preciso também repensar a formação do professor, para que ele reflita cada vez mais sobre sua função e adquira cada vez mais competência, não só em busca do conhecimento teórico, mas numa prática que se alimentará do desejo de aprender cada vez mais para poder transformar.

O preparo na formação do professor é de extrema importância. É necessário investir na própria formação lendo, conversando, pesquisando, buscando 
alternativas variadas, recriando e realizando práticas educativas lúdicas aliadas ao processo de ensino e aprendizagem. Quanto mais conhecimento tiver sobre o assunto, mais segurança o professor terá na aplicação e execução do trabalho.

Para Almeida (1987), dentre os aspectos básicos, é importante: conhecer a natureza do lúdico; conhecer os fins mais abrangentes, os fins mais específicos e os meios para que isso ocorra; conhecer profundamente causas e efeitos para possíveis respostas e encaminhamentos; conhecer as formas adequadas de implementação, considerando a adaptação na escola, a organização, o planejamento, a execução e a análise de qualidade, bem como da intervenção pedagógica realizada pelo professor como mediador entre o conhecimento científico e o conhecimento do senso comum adquirido pelo aluno.

O professor, antes de colocar em prática qualquer atividade lúdica, poderá organizar-se e traçar um plano de trabalho, levando em conta:

- A caracterização dos alunos e do ambiente: os alunos deverão ser considerados quanto à idade, sexo, cultura, nível socioeconômico; os educadores da escola, quanto à consciência prática, interesse. Já em relação ao ambiente, serão considerados os recursos materiais de que a escola dispõe: sala de aula, espaço, recursos didáticos.

- A adequação aos objetivos: o ato educativo é um ato consciente, histórico e planejado. Por isso é fundamental que, antes de concretizá-lo, definam-se as metas, prioridades, considerando para isso o perfil do aluno que se deseja formar, os conhecimentos que se deseja ensinar e quais os meios necessários para isso.

Nesse sentido, é importante distinguir dois aspectos referentes ao jogo e ao lúdico, para poder situá-los em relação aos objetivos: 1) A educação lúdica se resume nos seguintes aspectos: aprender a pensar; estimular suas faculdades intelectivas; dominar compreensivamente o conhecimento básico por si mesmo (satisfação-prazer); integrar-se na vida social; apropriar-se crítica e criativamente das situações do mundo e equilibrar-se emocionalmente (tendo em si uma vida mais feliz). 2) $\mathrm{Na}$ atividade lúdica, técnicas e jogos pedagógicos são meios que auxiliam a concretização de determinados objetivos específicos. O professor, tendo em mãos os dados do ambiente, poderá fazer um levantamento de jogos ou técnicas e enquadrá-los perfeitamente no plano escolar para auxiliar os alunos a dominarem um conhecimento referente a qualquer área de ensino. Esses recursos, denominados também de jogos-pedagógicos, têm um valor imprescindível e são absolutamente necessários, pois auxiliam a incorporação de sistemas abstratos e formais.

Quando se pensar em fazer qualquer tipo de atividade com os alunos, é preciso que eles estejam preparados para isso. Essa preparação ocorre na formulação de regras gerais, como: ter as mesmas oportunidades de participar; saber ouvir e saber o momento de falar; procurar se concentrar e ter atenção; não desvalorizar os que perdem; saber perder e ganhar; compreender o erro como possibilidade construtiva no processo de ensino e aprendizagem.

Pode-se, também, ter regras específicas a cada jogo, formuladas pelos próprios participantes. $\mathrm{Na}$ execução das atividades, o professor precisa ser a pessoa que realiza a mediação entre jogo e conhecimento; orienta e dinamiza; coloca-se de modo a não atrapalhar o andamento do jogo/brincadeira; anima, incentiva, problematiza e desafia; tem claros os objetivos almejados com a atividade; dá espaço para os alunos modificarem algumas regras, dependendo da atividade; possibilita aos alunos assumirem lideranças, dando-lhes espaço para conduzirem os jogos. Como diz Almeida: "O bom êxito de toda atividade lúdico-pedagógica depende exclusivamente do bom preparo e liderança do professor." (ALMEIDA, 1987, p.195).

Assim, a avaliação e análise constituem um processo contínuo de renovação que, dia a dia, vai se enriquecendo com várias vivências e experiências. Avaliar é um processo que estuda e interpreta os conhecimentos, habilidades e atitudes dos alunos. Não surge para punir, mas para verificar se aquilo que foi planejado e executado atingiu os objetivos para uma aprendizagem significativa em relação às mudanças de comportamento.

Os jogos em si não constituem instrumentos de avaliação, mas são estratégias didáticas que devem ser usadas e que oferecem ao professor e aos próprios alunos a possibilidade de observarem a sua aprendizagem, as atitudes e a eficiência do próprio trabalho educativo. 
CONFECÇÃO E DESENVOLVIMENTO DO JOGO: uma mediação para a aprendizagem de Química no Ensino Médio

O jogo foi desenvolvido com uma turma de 23 (vinte e três) estudantes da primeira série do Ensino Médio Técnico em Informática do Instituto Federal do Paraná/IFPR localizado na cidade de Assis Chateaubriant.

As aulas iniciaram-se com a professora da disciplina, que é uma das autoras do trabalho aqui apresentado, introduzindo o conteúdo de estrutura atômica, no qual evoluíram os conceitos sobre elementos químicos e suas descobertas e também foram contextualizados alguns elementos químicos, ao mesmo tempo em que se dizia o nome e o símbolo dos elementos químicos de forma contextualizada.

$\mathrm{Na}$ aula anterior à aplicação dos jogos, os estudantes foram informados sobre o desenvolvido do jogo. Foi sugerido a eles que utilizassem a tabela periódica para reconhecer elementos e símbolos não tão conhecidos.

Para a confecção do jogo contou-se com cartelas do bingo publicadas no livro "Jogos didáticos de Química” (CUNHA, 2000). As cartelas foram confeccionadas em folha de papel sulfite, e posteriormente recortadas uma a uma. Cada cartela possuía 15 (quinze) símbolos de diferentes elementos químicos, conforme mostra a figura 1 .

Figura 1 - Cartelas utilizadas para desenvolvimento do jogo

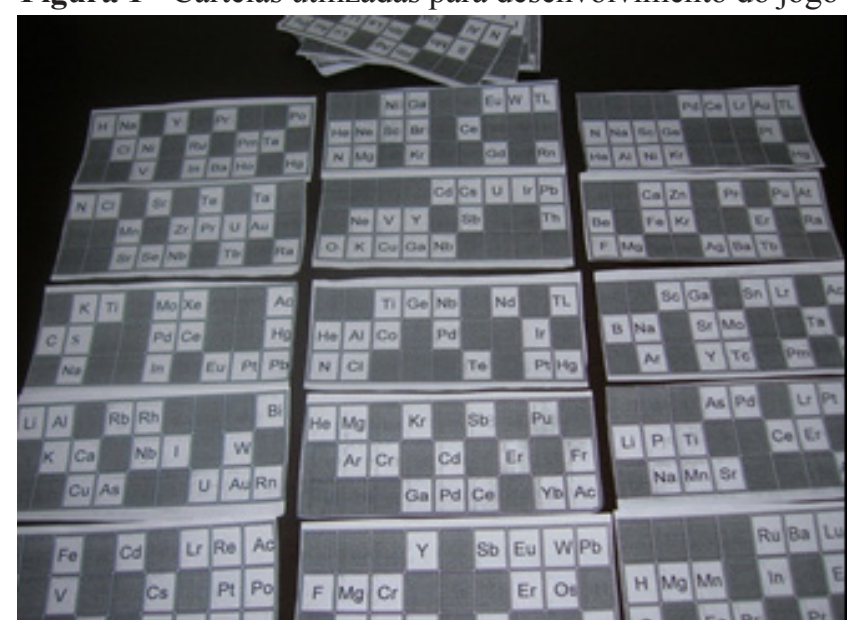

Os elementos químicos foram sendo sorteados, e os seus respectivos nomes escritos no quadro. Para que pudessem jogar, os estudantes deveriam lembrar os símbolos dos elementos sorteados.
E para marcar os elementos nas cartelas, foram utilizados grãos de feijão.

Para cada estudante foi entregue uma cartela e quem a preenchesse primeiro ganhava o jogo. Como incentivo, havia prêmios que eram chocolates, pirulitos e balas para o primeiro, segundo e terceiro lugar, respectivamente. Quando houvesse o primeiro ganhador, ele receberia uma nova cartela para que pudesse continuar na brincadeira sem perturbar os demais, tendo assim a oportunidade de ganhar novamente. Pediu-se que cada estudante não divulgasse seus símbolos, incentivando todos para que tentassem lembrar os símbolos, sem esperar pela resposta.

Posteriormente à aplicação do jogo foi entregue um questionário aos alunos para que avaliassem a atividade lúdica e também para que escrevessem os símbolos e/ou os nomes de alguns elementos químicos, com o intuito de avaliar o grau de contribuição desse recurso didático na aprendizagem, após o desenvolvimento da atividade.

Além do questionário, utilizou-se a observação participante (LUDKE; ANDRÉ, 1986) para a análise dos dados referentes à importância do jogo no desenvolvimento de uma prática pedagógica mais crítica, criativa e significativa.

\section{Resultados e discussão}

Primeiramente foi possível observar que o jogo didático contribuiu de forma significativa para aumentar o interesse dos alunos pela disciplina de Química, uma vez que, quando foram informados sobre o desenvolvimento da atividade, houve demonstração de interesse em estudar os nomes e símbolos para que assim conseguissem participar da atividade.

Os estudantes estavam motivados em aprender, postura diferente da apresentada por eles quando da introdução do conteúdo, pois achavam que conhecer todos os nomes e símbolos dos elementos químicos seria muito difícil.

No desenvolver da atividade, conforme os nomes dos elementos que eram sorteados, foi possível observar que todos os alunos já haviam aprendido os símbolos dos elementos químicos mais comuns. Para os elementos químicos não tão comuns - como, por exemplo, o zircônio, o antimônio e o 
escândio - poucos alunos lembravam seus símbolos. Assim, pedia-se a um deles que informasse o símbolo e o escrevesse no quadro para que os demais pudessem reconhecê-lo.

A dinâmica do desenvolvimento do jogo proporcionou a participação de todos os estudantes e, conforme Kishimoto (2001), as características lúdicas e educativas estiveram presentes e puderam ser confirmadas pela postura apresentada pelos estudantes durante a atividade.

$\mathrm{Na}$ tabela 1 segue a porcentagem e o número de alunos que responderam à questão que indagava sobre suas opiniões em relação ao uso de jogos para ensinar Química.

Tabela 1 - Número e porcentagem das respostas da questão 1

\begin{tabular}{c|c|c}
\cline { 2 - 3 } & $\begin{array}{c}\text { Número de } \\
\text { respostas }\end{array}$ & $\begin{array}{c}\text { Percentual } \\
\text { de respostas }\end{array}$ \\
\hline Gostei Muito & 21 & $91,3 \%$ \\
\hline Gostei Parcialmente & 1 & $4,3 \%$ \\
\hline Não gostei & 1 & $4,3 \%$ \\
\hline Total de Respostas & 23 & $100 \%$ \\
\hline
\end{tabular}

A figura 2 apresenta os resultados obtidos quando os alunos foram questionados sobre a atividade desenvolvida.

Figura 2 - Resultados obtidos quando questionados sobre a atividade desenvolvida

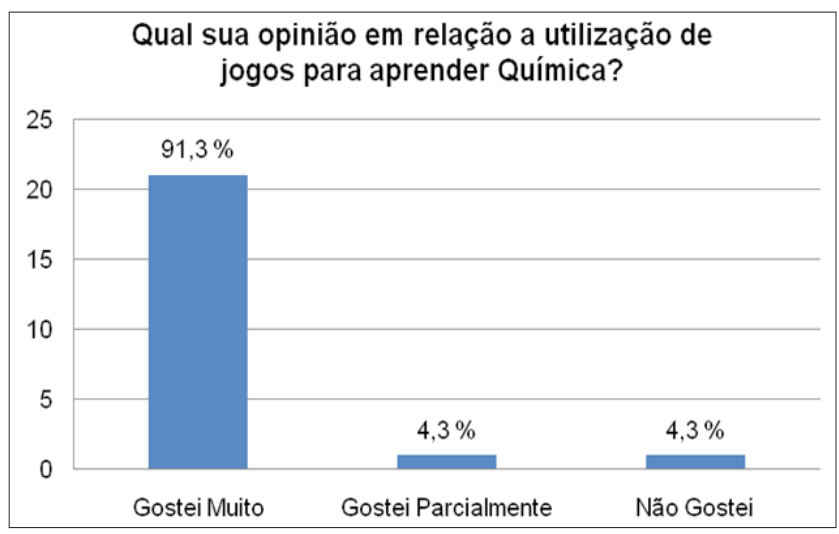

Esses resultados demonstram que dos 23 estudantes que responderam ao questionário, 21 gostaram da atividade com o jogo de bingo para aprender conteúdos de Química. Várias foram às justificativas dadas pelos estudantes: alguns responderam que o jogo possibilitou o reconhecimento de elementos e nomes de forma descontraída; outros disseram que a atividade proporcionou uma aula diferente da habitual, em que todos participaram buscando obter respostas corretas. Quando ocorria erro em relação à resposta, os estudantes já verificavam onde haviam errado e esse processo, segundo eles, possibilitou o aprendizado do conteúdo trabalhado.

Outra justificativa dada pelos estudantes foi a de que a prática do jogo mostrou-se eficiente, pois gostaram de aprender brincando, salientando que diversão e ensino podem acontecer ao mesmo tempo. A satisfação que os alunos demonstraram durante a realização do jogo de bingo possibilitou entendermos a importância da utilização de recursos didáticos nas aulas de Química, pois possibilita a participação efetiva do estudante na construção do conhecimento.

Consideramos que tanto os estudantes como o professor vivenciaram momentos de aprendizagem, cada qual dentro de uma perspectiva. Os estudantes, por sua vez, demonstraram atenção durante o desenvolvimento do jogo. Verificamos, no final da atividade, que eles apresentavam conhecimentos sobre vários elementos, conseguindo relacionar símbolo e nome, exemplificando a presença desses elementos em materiais, tecnologias e produtos do seu cotidiano. Expressavam comentários sobre a presença de elementos como o flúor na água potável, o cálcio nos ossos e em alimentos derivados do leite, o potássio na banana, entre outros. Essas relações ajudam os estudantes a perceber como a Química está presente em suas vidas, seja pela alimentação ou fazendo parte do funcionamento de seu organismo.

Por outro lado, o professor pôde perceber a diversidade de situações que estão presentes durante a realização de um jogo como recurso didático em aulas de Química. Citamos como exemplo: a interação entre professor e estudantes; a revisão de conteúdos; a motivação para o estudo; o desenvolvimento da capacidade de liderança e competitividade; a livre expressão das emoções estimuladas pela participação no jogo; a valorização do diálogo como forma de expressar opiniões e conhecimento; a tomada de decisão e autonomia. Além dessas situações presenciadas, o professor tem a oportunidade de trabalhar no sentido de promover a liberdade de seus alunos e levá-los a superar os possíveis limites que possam ter em atividades realizadas em sala de aula, levando-as para a vida cotidiana.

Apenas um estudante respondeu que gostou parcialmente da atividade com o jogo. Verificou-se 
que esse recurso didático foi indicado para substituir aulas que utilizam basicamente como recurso a projeção de slides. Segundo as respostas, os jogos são opções interessantes para as aulas de Química, pois possibilitam a participação mais efetiva dos estudantes.

Somente um estudante não gostou da atividade, pelo fato de não ganhar o jogo de bingo nenhuma vez; ao mesmo tempo, justificou que o jogo foi bom, pois teve a oportunidade de aprender a matéria.

A tabela 2 mostra o total de respostas e a porcentagem de respostas dos alunos quando perguntados se gostariam de que outros conceitos químicos fossem abordados por meio de jogos.

Tabela 2 - Número e porcentagem das respostas da questão 2

\begin{tabular}{c|c|c}
\cline { 2 - 3 } & $\begin{array}{c}\text { Número de } \\
\text { Respostas }\end{array}$ & $\begin{array}{c}\text { Percentual de } \\
\text { respostas }\end{array}$ \\
\hline Sim & 21 & $91,3 \%$ \\
\hline Às vezes & 2 & $8,7 \%$ \\
\hline Não & 0 & $0.0 \%$ \\
\hline Total de respostas & 23 & $100 \%$ \\
\hline
\end{tabular}

A figura 3 apresenta o grau de interesse da turma em aprender novos conteúdos químicos por meio de jogos.

Figura 3 - Resultados em relação ao interesse dos estudantes para que novos conteúdos sejam trabalhados por meio de jogos

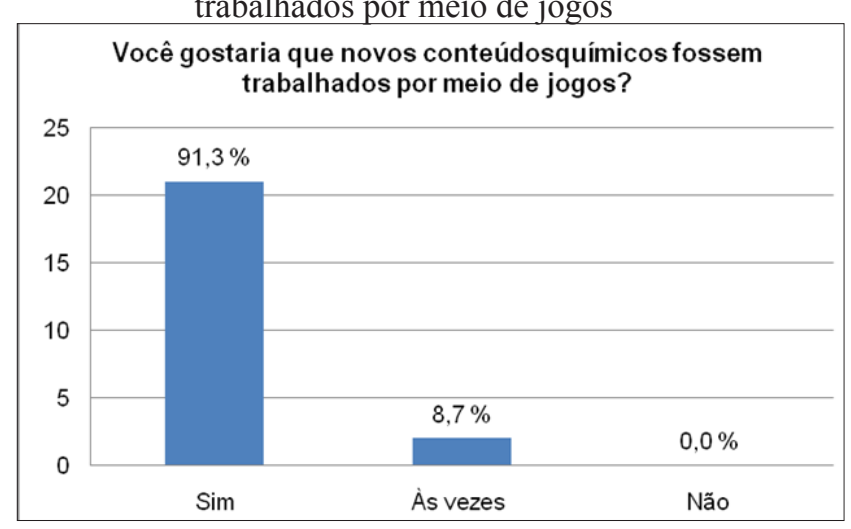

Nessa questão, 21 estudantes responderam que gostariam que jogos fossem utilizados para desenvolver outros conteúdos. Enquanto jogavam, os estudantes demonstravam em suas falas o interesse pela atividade, ressaltando que em outros momentos, com conteúdos diferentes, seria bom utilizar um jogo para complementar os conhecimentos já trabalhados, como uma forma diferente de realizar exercícios de aprendizagem.

Apenas dois estudantes responderam que, às vezes, gostariam que jogos fossem utilizados para desenvolver outros conteúdos. Consideramos esse valor percentual baixo, e isso demonstra que a atividade apresentou um bom índice de aceitabilidade pelos estudantes.

Uma terceira opção de resposta, "não gostei desse tipo de atividade", não foi assinalada; esse resultado evidenciou que nenhum estudante considerou ruim a atividade com jogos.

A tabela 3 apresenta dados referentes à pergunta em que os alunos que participaram da pesquisa opinaram sobre a contribuição do uso do jogo para reconhecimento de simbolos e nome dos elementos químicos.

Tabela 3 - Número e porcentagem das respostas da questão 3

\begin{tabular}{c|c|c}
\cline { 2 - 3 } & $\begin{array}{c}\text { Número de } \\
\text { respostas }\end{array}$ & $\begin{array}{c}\text { Percentual de } \\
\text { respostas }\end{array}$ \\
\hline Sim & 22 & $95,6 \%$ \\
\hline Parcialmente & 1 & $4,4 \%$ \\
\hline Não & 0 & $4,3 \%$ \\
\hline Total de Respostas & 23 & $100 \%$ \\
\hline
\end{tabular}

A figura 4 mostra os resultados obtidos em relação à assimilação do conteúdo pelos estudantes.

Figura 4 - Resultados obtidos quanto à compreensão do conteúdo

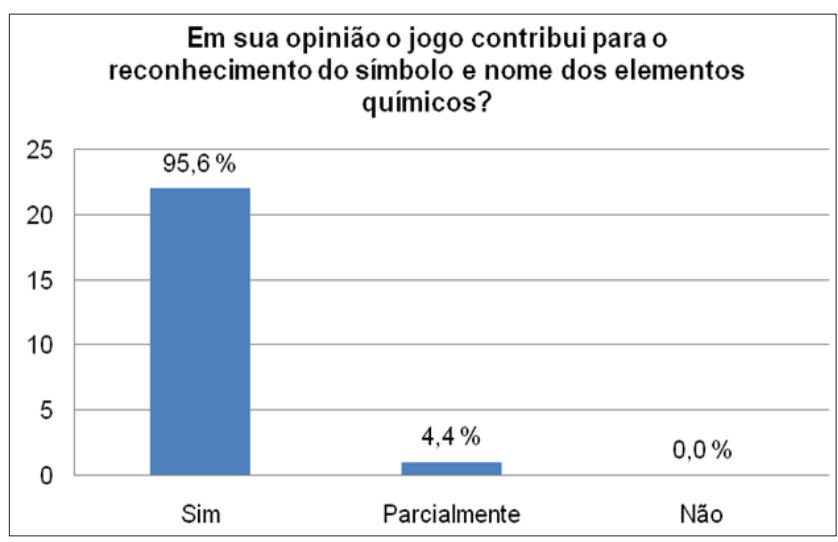

Dos resultados obtidos, 22 estudantes responderam que o jogo auxiliou no reconhecimento do símbolo com seus respectivos nomes. Ao concluir a atividade foi retomado o diálogo estabelecido na introdução do 
conteúdo, quando os estudantes afirmaram que seria complicado guardar tantos símbolos e nomes de elementos, que isso seria praticamente uma tarefa impossível. Na ocasião explicou-se que não era necessário memorizar todos os elementos químicos da tabela periódica, que durante as aulas e nas várias atividades que seriam desenvolvidas no decorrer da disciplina os símbolos e nomes acabariam sendo conhecidos.

No final do jogo retomou-se o diálogo e demonstrou-se para os estudantes que o jogo possibilitou a eles o reconhecimento dos elementos de forma descontraída, uma vez que foram feitas relações quanto à presença dos diferentes elementos principalmente em tecnologias do cotidiano, relacionando-se a Química com a Ciência e o desenvolvimento tecnológico.

Apenas um estudante respondeu que o jogo contribuiu parcialmente para o reconhecimento dos símbolos e nomes de elementos, e nenhum estudante respondeu que o jogo não contribuiu.

Em outra questão foi solicitado aos estudantes que marcassem "verdadeiro ou falso" para nomes e símbolos de 11 elementos químicos dispostos em uma tabela, e estes estão representados na tabela 4 .

Tabela 4 - Número e porcentagem das respostas da questão 4

\begin{tabular}{c|c|c}
\cline { 2 - 3 } & $\begin{array}{c}\text { Número de } \\
\text { respostas }\end{array}$ & $\begin{array}{c}\text { Percentual de } \\
\text { respostas }\end{array}$ \\
\hline Acertos & 14 & $61 \%$ \\
\hline Erros & 10 & $39 \%$ \\
\hline Total de Respostas & 23 & $100 \%$ \\
\hline
\end{tabular}

A figura 5 apresenta a relação entre acertos e erros obtidos para essa questão.

Figura 5 - Resultados dos acertos após desenvolvimento do Jogo Bingo Químico

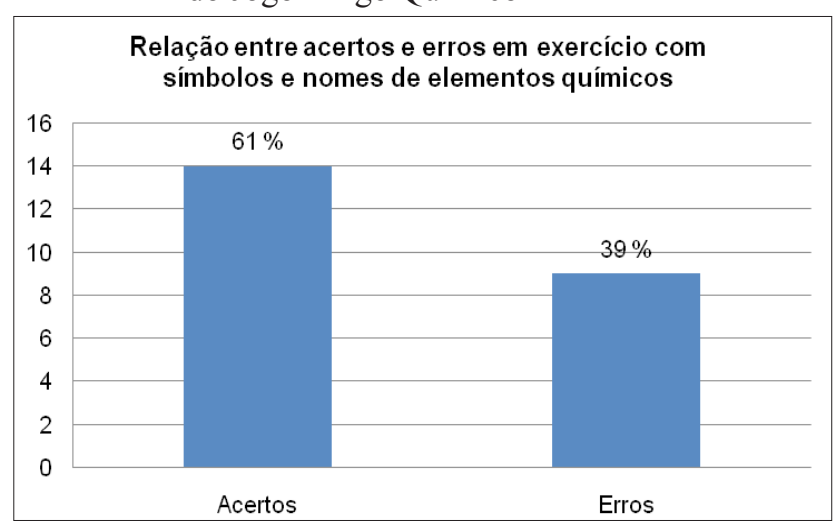

Dos 23 estudantes, 14 responderam a todas as questões da tabela corretamente, demonstrando claramente que a utilização do jogo possibilitou a aprendizagem dos conhecimentos químicos. Essa aprendizagem aconteceu de forma lúdica, os estudantes puderam fazer as relações entre nomenclatura e símbolo, entretanto a aprendizagem aconteceu à medida que eles perceberam a presença de elementos químicos até então desconhecidos em sua vida cotidiana. Conforme o depoimento de um estudante, "a Química está presente em tudo, o jogo possibilitou ampliar as possibilidades de aprendizagem".

Outros nove estudantes apresentaram erros no preenchimento da tabela. Ressaltamos que esses estudantes apresentaram boa quantidade de acertos também, mas optamos em diferenciar apenas aqueles que obtiveram aproveitamento de $100 \%$ de acerto em relação aos que apresentaram percentual diferente desse, para melhor comparação. Nenhum estudante obteve $100 \%$ de erro no exercício, entretanto alguns estudantes apresentaram dificuldade em associar símbolos com os respectivos nomes, principalmente quando a alternativa era falsa e havia necessidade de realizar a correção.

Em exercício realizado anteriormente ao jogo os estudantes apresentaram resultados pouco satisfatórios. Comparando esses resultados com os obtidos após o jogo, pode-se comprovar que houve melhora significativa quanto ao crescimento dos estudantes em relação ao conteúdo desenvolvido. Observamos que as interações ocorridas entre os estudantes e entre professor e estudante proporcionaram momentos de troca de conhecimentos, de participação e colaboração mútua. Além de apresentar melhora em relação ao conhecimento, pode-se constatar que o lúdico é uma forma eficiente de trabalhar os conteúdos químicos quando o professor realiza um bom planejamento em relação à utilização de jogos.

\section{Considerações finais}

A utilização do jogo "Bingo Químico" para aula de Química mostrou-se um recurso didático que surpreendeu os professores. Constatamos que essa atividade desempenhou sua função, pois tanto o caráter educativo quanto o lúdico foram nela observados. A partir dessa prática podemos refletir sobre nossa ação enquanto professores e, ao mesmo 
tempo, apontar pontos que constatamos com a atividade do jogo.

É importante destacar que o uso dos jogos como recurso didático tem o intuito de proporcionar o exercício de reflexão na ação para posterior intervenção e mediação para uma aprendizagem mais significativa, buscando ultrapassar os pontos falhos. O jogo mostrou-se como um recurso fundamental para o ensino de Química, entretanto é necessário que o professor incorpore nessa prática o ato da pesquisa como estratégia de ação e intervenção.

\section{Referências}

ALMEIDA, P. N. de. Educação lúdica, técnicas e jogos pedagágicos. 5. ed. São Paulo: Loyola, 1987.

ANTUNES, C. Jogos para estimulação das múltiplas inteligências. Rio de Janeiro: Editora Vozes, 1998.

COSTA, G. S. et al. A criação de um jogo de tabuleiro como instrumento de complementação de uma atividade de educação ambiental. In: ENCONTRO NACIONAL DE ENSINO DE BIOLOGIA, 1; ENCONTRO REGIONAL DE ENSINO DE BIOLOGIA: RJ/ES, 3, 2005, Rio de Janeiro. Anais... Rio de janeiro: Sociedade Brasileira de Ensino de Biologia, 2005. p. 68-70.

CUNHA, M. B. Jogos no ensino de química: considerações teóricas para sua utilização em sala de aula. Química Nova na Escola. v. 34, n.2, p.92-98, maio 2012.

2000.

. Jogos didáticos de química. Santa Maria: Grafos,

FRIEDMANN, A. Brincar, crescer e aprender: o resgate do jogo infantil. São Paulo: Moderna, 1996.

GODOI, T. A.; OLIVEIRA, H. P. M.; CODOGNOTO, L. Tabela periódica: um super trunfo para os alunos de ensino fundamental e médio. Química Nova Na Escola, v. 32, n.1, p.22-25, fevereiro 2010 .

HUIZINGA, J. Homo Ludens. 4. ed. São Paulo: Perspectiva, 1999.

LEIF, J.; BRUNELLE, L. O Jogo pelo jogo: a atividade lúdica na educação de crianças e adolescentes. Rio de Janeiro: Zahar, 1978.

LÜDKE, M.; ANDRÉ, M. E. D. A. Pesquisa em educação: abordagens qualitativas. São Paulo: EPU, 1986.

SANTANA, E. M. Bingo químico: uma atividade lúdica envolvendo símbolos e nomes dos elementos. Disponível em: $<$ http://www.senept. cefetmg.br/galerias/Arquivos senept/anais/terca_tema1/TerxaTema1Poster2 .pdf $>$ Acesso em: 13 agosto 2012 .
SOARES, M. H. F. B. Jogos para o ensino de química. Guarapiri: Exlibris, 2008.

; OKUMURA, F.; CAVALHEIRO, É. T. G. Proposta de um jogo didático para ensino do conceito de equilíbrio químico. Química Nova na Escola, n. 18, p. 13-17, 2003.

KISHIMOTO, T. M. O jogo e a educação infantil. São Paulo: Pioneira, 1996.

. Jogo, brinquedo, brincadeira e a educação. 2. ed. São Paulo: Cortez, 2001.

PIAGET, Jean. A formação do símbolo na criança. Guanabara Koogan, Rio de Janeiro, 1978.

Seis estudos de psicologia. 24. ed. Rio de Janeiro: Florense Universitária, 2005.

Data de submissão: 26/09/2012

Data de aceite: 24/11/2012 